\title{
Genomic Equivalents per Milliliter
}

National Cancer Institute

\section{Source}

National Cancer Institute. Genomic Equivalents per Milliliter. NCI Thesaurus. Code C161492.

A unit of concentration defined as the number of genomic equivalents per milliliter. 